\title{
NiCE Teacher Workshop: Engaging K-12 Teachers in the Development of Curricular Materials That Utilize Complex Networks Concepts
}

EMMA K. TOWLSON, Northeastern University (USA)

LORI SHEETZ, U. S. Military Academy at West Point (USA)

RALUCCA GERA, Naval Postgraduate School (USA)

JON W. ROGINSKI, U.S. Military Academy at West Point (USA)

CATHERINE B. CRAMER, Columbia University (USA)

STEPHEN UZZO, New York Hall of Science (USA)

HIROKI SAYAMA, Binghamton University (USA)

Our educational systems must prepare students for an increasingly complex and interconnected future, but teachers facing this task are not equipped to prepare students to succeed. Network science-the study of how biological, social, physical and technological systems interconnect, how the structure of those connections evolve over time, and how those structures and behaviors inform our understanding of them-is a pathway to deepening engagement with the kinds of complex problems these students will have to deal with as adults in the workforce. We recently held the Networks in Classroom Education (NiCE) workshop for a group of $21 \mathrm{~K}-12$ teachers with various disciplinary backgrounds. The explicit aim of the workshop was to introduce them to concepts in network science, show them how these concepts can be utilized in the classroom, and empower them to develop resources using these concepts, in the form of lesson plans, for themselves and for the wider community. Here we detail the nature of the workshop and present its outcomes, including a set of publicly available innovative lesson plans. We also discuss the future development of the successful integration of network science in K-12 education and its importance in inspiring and enabling our teachers.

\section{Introduction, Background and Motivation}

We live in a highly interconnected world. Intercontinental transportation has never been easier, communication is instantaneous across the globe, and technology drives ever more additions to our personal networks. This connectivity - and the networks that describe it - has enormous implications for everything from information propagation, to the stability of ecosystems, to the spread of disease. It is clear that networks are ever more important to understand if we wish to

Complicity: An International Journal of Complexity and Education

Volume 15 (2018), Number 1・pp. 5-18 
successfully navigate our world (Harrington, Beguerisse-Díaz, Rombach, Keating, \& Porter, 2013). Yet our formal education systems do not adequately reflect this modern reality, instead remaining surprisingly modular, with subjects taught in an isolated, linear fashion.

Network science is the study of real-world networks, systems that can be described as a collection of nodes connected by links, such as our social networks (in which people and groups of people are interconnected via friendship, kinship, or work) and transportation networks (in which cities are connected by roads, trains, or air traffic). Network science touches nearly all disciplines. It is used to study neuronal networks in the brain with implications for cognition and mental disorders, as well as genomic and proteomic networks with implications for curing genetic diseases, through personalized medicine as well as understanding and addressing the spread of disease within and among organisms. A young and highly interdisciplinary field, network science brings together the mathematics of graph theory and statistics with the systemspecific knowledge of real complex systems to better understand their structure and behavior. Currently the formalism of network science is not taught until graduate school, yet many of its concepts and tools are highly accessible - especially with the advent of user-friendly software both to the non-academic and to students of all ages.

In this paper, the term "network science" is used to mean the scientific field of the study of networks. We will also refer to: (i) network thinking to mean the habits of mind that explicitly acknowledge connections (between modules, subjects, or entities) and derives new information about what phenomena the systems represent; (ii) network concepts to mean specific ideas, such as the notion of hubs, which represent important and well connected nodes; and (iii) network tools to mean mathematical or computational network science tools, such as how to calculate the importance of a person in a social network, or software to visualize the structure of the network. Network thinking, concepts, and tools have the potential for broad impacts, including in a style of teaching that facilitates cross-disciplinary learning in a manner suited to the intuitive way in which children think (Bassett \& Mattar, 2017).

In previous projects, developed to bring network science and network-thinking to high school students (Cramer et al., 2018, 2015; Sayama, Cramer, Sheetz, \& Uzzo, 2017), we identified an unfilled need for accessible network-related educational resources. Even for the graduate and undergraduate level student, such resources are new and few in number (Barabási, 2016). This motivated the development of Network Literacy: Essential Concepts and Core Ideas (Cramer, Porter, Sayama, Sheetz, \& Uzzo, n.d.; Sayama, Cramer, Porter, Sheetz, \& Uzzo, 2016), which forms the framework for a basic understanding of networks. It is now available in 20 languages. The next step is to build on this foundation and create and disseminate high quality network science related resources for use in school instruction across disciplines, and across grades.

In the NiCE workshop we aimed to produce lesson plans that make use of network science in order to aid in teaching certain specific topics and ideas, identified by the teacher that may be difficult for students to understand except by rote, and as such deepen student engagement in those topics. However, to realize these lesson plans there is a need to synthesize two distinct skillsets: that of the practicing network scientist, and that of the practicing teacher. The network scientist brings the subject-specific knowledge and scientific expertise, while the teacher brings the wealth of classroom experience and command of formal lesson design. Through this workshop we discovered that - with effective collaboration between these two skillsets - network science can be brought to the classroom in a way that enhances the existing curriculum and

Complicity: An International Journal of Complexity and Education

Volume 15 (2018), Number $1 \bullet p p .5$ - 18 
highlights connections between topics and subjects. Furthermore, areas of difficulty for the teachers themselves that may be eased with network science tools - such as in lesson design or in the meeting of education standards, e.g. the Next Generation Science Standards or NGSS - can be identified. Both parties are of the utmost importance in this process and, ideally, the lead should be taken by the practitioner: the teacher.

We recognized that the shift in thinking associated with network science is something that teachers need support for. When learning alongside their students, the comfort level of teachers was very low: they are accustomed to being the authority in the classroom. We therefore identified a need to create a space for teachers to learn, and gain ownership of the initiative of bringing network science and network-thinking to their schools. This led to the conception of the NiCE workshop.

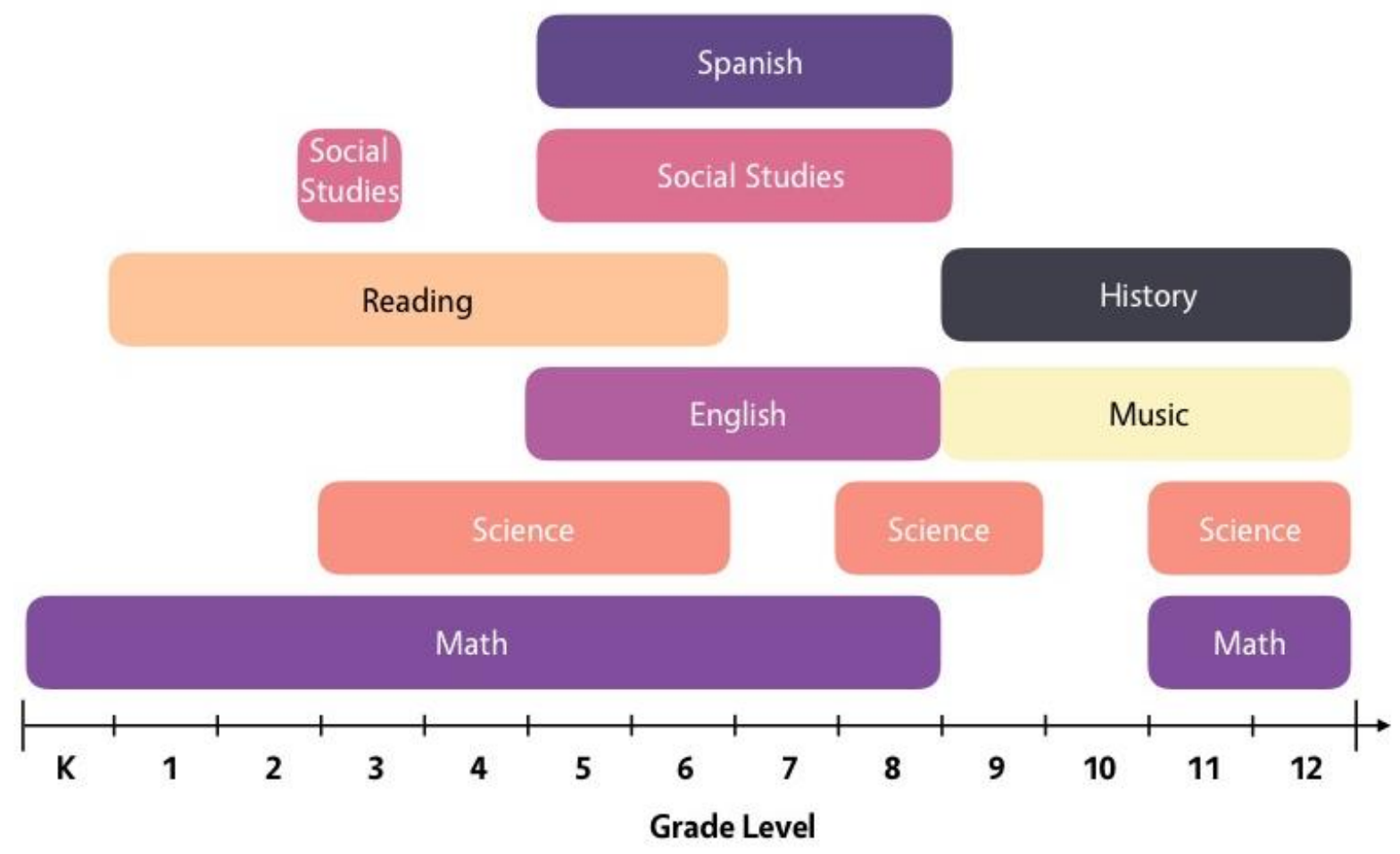

Figure 1. Coverage of Grades and Subjects by Skillsets of Workshop Participants. Each subject is represented as a sequence of boxes, and their placement along the $x$ axis illustrates the presence of a teacher qualified to teach the subject at a given grade level. Educators who attended the workshop have highly diverse skillsets, both in terms of age/grade level of student, and specialist subjects. K-12 grade levels were successfully spanned, with good representation in most curricular areas. Note also that one teacher specializes in professional development, and another in intervention; they are not displayed in the figure.

\section{Concept}

Our vision of network science and education is that network science should be (a) pervasive as a way of thinking regardless of subject area; and (b) something that helps teachers with their

Complicity: An International Journal of Complexity and Education

Volume 15 (2018), Number $1 \bullet p p .5$ - 18 
existing tasks (Sheetz, Dunham, \& Cooper, 2015). A teacher's job is extremely demanding, and necessarily involves meeting a number of governmental standards. Indeed, with the introduction of the NGSS arriving in parts of the USA ("Next Generation Science Standards (NGSS)," n.d.), teachers of scientific subjects face the extra challenge of an official move toward connected thinking, in the form of "cross-cutting concepts". The NGSS were released in 2013, and aim to elicit a shift to a more holistic approach to science, as opposed to segregated subjects. They rest on three dimensions - content (i.e. theory), practice, and cross-cutting concepts. These dimensions are intended to teach the interplay between theory and practice, and the recognition that certain concepts are common to many topics. (At the time of the workshop, the teachers from the West coast had been subject to advanced training in these standards for at least a year and those from the East coast had not, which aided in cross-mentorship in the NiCE workshop.) We believed that network science and network thinking would be well-suited to tackling these new requirements, which demand a significant change in approach.

We also believed, going into the workshop, that resources for teachers are best developed by teachers themselves. No one else has more intimate knowledge of the job requirements of a teacher, the official standards, the needs of the students, and the types of lessons and activities that will be successful in a classroom setting. We therefore aimed to empower and enable this development. By educating teachers on network concepts, providing a creative and comfortable environment within which to spark ideas, and providing the support and expertise of practicing network scientists, we set out to foster the ideal first focus group to create such resources. We wanted to show the education community the ways that network science can be a tool for their teaching, and inspire teachers to take ownership of their own network science related initiatives.

\section{Execution}

To realize and validate our ideas, we organized and structured the Networks in Classroom Education (NiCE) workshop to directly address them. We invited applications from teachers in a number of schools and locations in the regions of the organizers (predominantly on the East and West coasts of the USA). These were chosen to ensure our ability to provide adequate pre- and post-workshop support. From the applications, we selected 21 individuals to attend the workshop. These educators together brought more than 300 years of accumulated teaching experience and a highly diverse set of skills. Their knowledge spanned subjects including math, English, Spanish, science, social studies, history, and music, and represented all grade levels from K-12, plus educational coaches (see Figure 1).

We held the workshop at the United States Military Academy at West Point (USMA) over the course of four days, two full and two partial, in July 2017, deliberately chosen so as to be nonintrusive on school or holiday time. We also provided a small stipend to remunerate teachers for their significant efforts. The schedule included a blend of lectures, discussion groups, and interactive/hands-on sessions - see Table 1 for a summary of the program, and the workshop website for more details ("Networks in Classroom Education (NiCE) Teacher Workshop," 2017). For the purpose of effective collaboration, teachers were seated in five groups, each with a different focus area according to their grade level: K-2nd grade, 3-5th grade, 6-8th grade, High School, and Educational Coach. Each group was partnered with a network scientist, from the

Complicity: An International Journal of Complexity and Education

Volume 15 (2018), Number $1 \bullet p p .5-18$ 
Center for Complex Network Research (CCNR) at Northeastern University, the USMA Network Science Center, or the New York Hall of Science (NYSCI). This

\section{Day 1 (evening): Welcome dinner and movie}

Social time and dinner

Introductions and brainstorming on network concepts

Movie: Connected

\section{Day 2: Hands on network science and concept development}

Introduction to network science (presentation)

Spelling and networks (activity)

Network Literacy Essential Concepts and Core Ideas (presentations)

NGSS and network science (presentation and activity)

Brainstorming - network questions and applications

Team work, creating ideas for lesson plans

Introduction to Gephi - hands-on

Spreading on networks (presentation)

Developing networks from module ideas (activity)

Group speed rounds

Tour of West Point

\section{Day 3: Lesson planning, development, and rehearsal}

Developing lesson plans

Network robustness (activity)

Developing network of governing standards of module, refining lesson plans

Group speed rounds and feedback

Boat ride

Refining lesson plans, preparing outputs

Complicity: An International Journal of Complexity and Education

Volume 15 (2018), Number 1・pp. 5-18 
Group speed rounds and feedback

\section{Day 4 (morning): Group outbriefs}

Post workshop survey

Group outbriefs

Table 1. Schedule Overview

Please note that further details are available on the NiCE workshop website ("Networks in Classroom Education (NiCE) Teacher Workshop," 2017).

partnering was intended to facilitate the collaborations and sharing of ideas between teachers and network scientists that we imagine to be at the crux of effective lesson design. The four days of the workshop consisted of the following elements:

Day 1: Prior to the workshop, participants were asked to review three short online videos to introduce the idea of network science ("Networks in Classroom Education (NiCE) Teacher Workshop," 2017). The workshop began with a low-key evening intended for introductions, motivating the themes and goals of the workshop, and brainstorming existing conceptions of networks and any questions people had from the pre-workshop material.

Day 2: The first full day introduced crucial network science concepts and reviewed the structure and standards for modules and lesson plans (with a focus on the NGSS ("Next Generation Science Standards (NGSS)," n.d.)). This was accomplished via presentations, hands-on activities, and group and whole-room discussions. The intention of this day was to lay the groundwork for resource development, by educating about network science and helping the teachers identify key areas that could benefit from the network science lens. We concluded the day with a tour of USMA.

Day 3: The second full day was benchmarked for substantial development of lesson plans and projects. It included a hands-on network science activity and the mapping of standards for curricular modules. We arranged for an afternoon boat ride, to foster working relationships, inspiration, and creativity.

Day 4: On the final morning, the teachers presented their materials and were provided instructions for completing their projects for review and were asked to do this within two weeks of departure. They were also asked to complete a post-workshop survey, so that we could gather more metrics with which to gauge its success and impact (see Outcomes section below), and information about the best ways to move forward.

At multiple stages throughout the workshop the groups were given the opportunity to present their ideas and progress on lesson plans in order to gather feedback from network scientists and the other participants. This allowed everyone to incorporate a variety of suggestions and fully develop their concepts. 
(a)

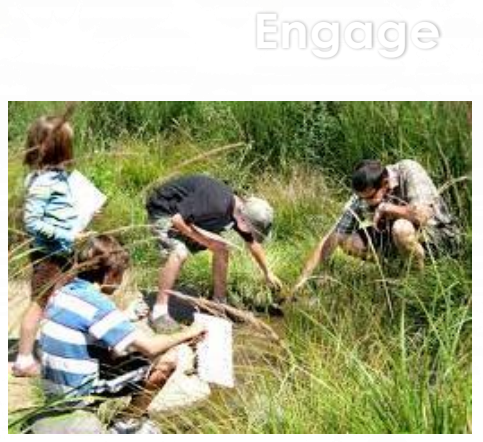

(b)

What do you
notice about the
plants in our environment?

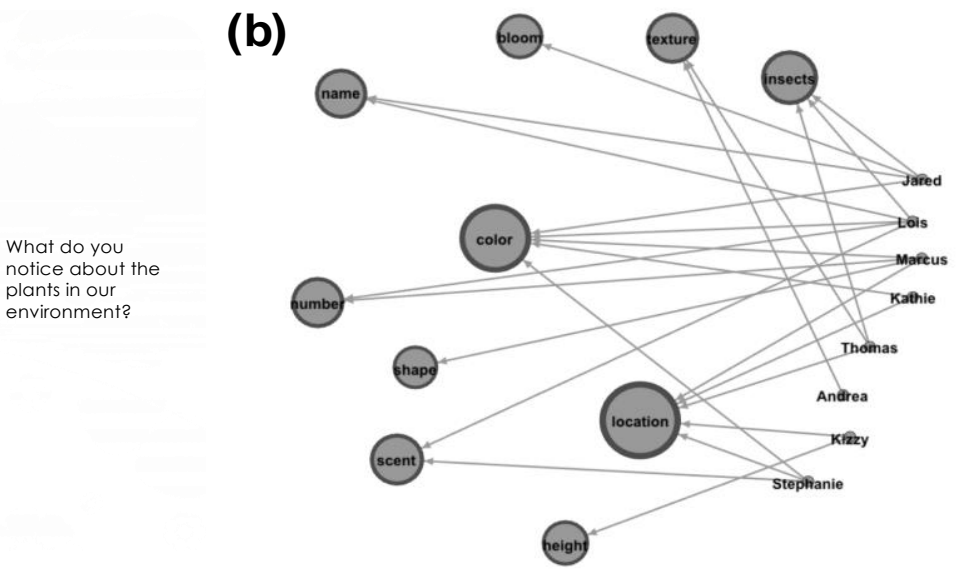

(c)

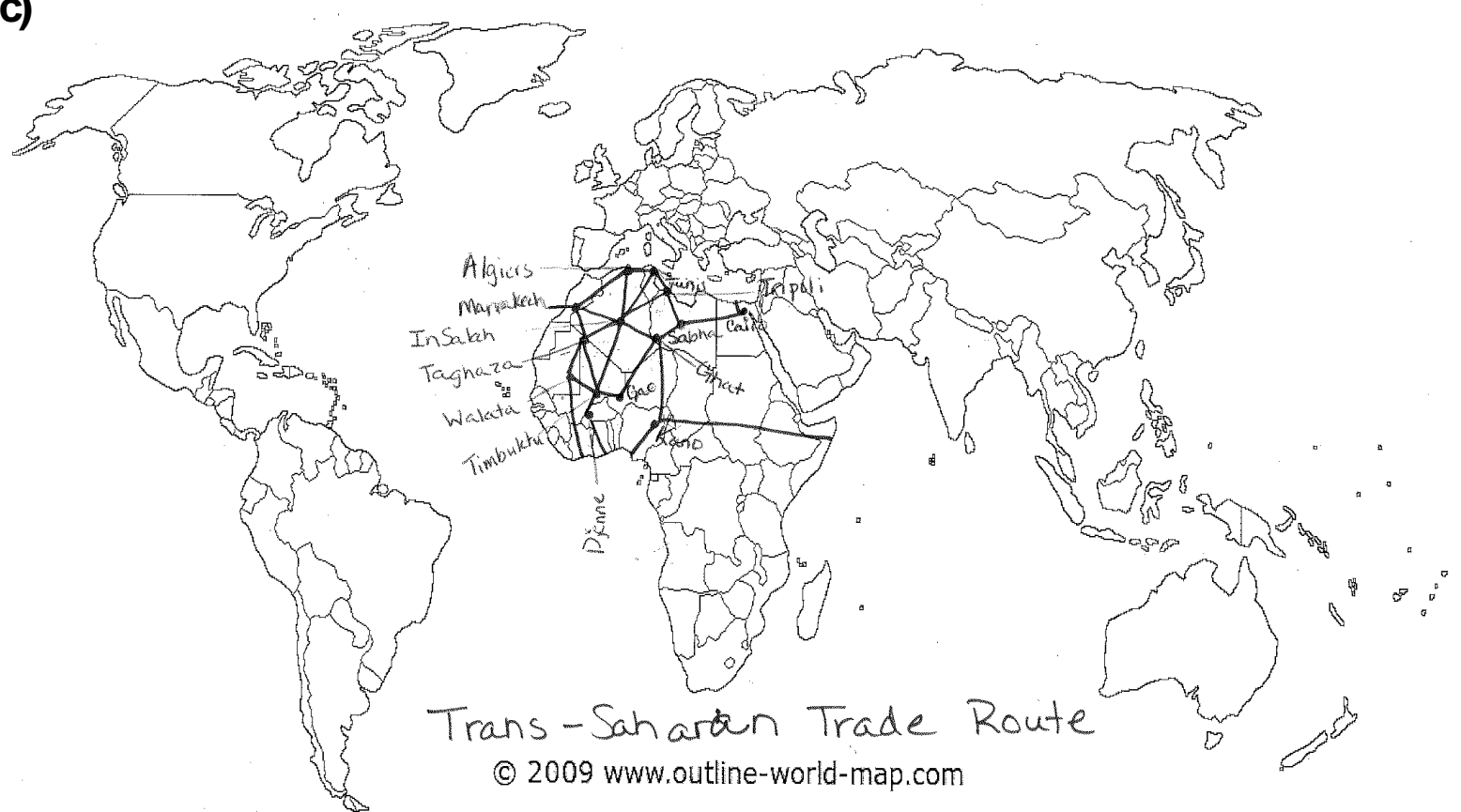

Group Questions:

1. In Salah \&Timbuktu

2. Southern cities have gold, and northern cities have salt.

4. Location near salt or gold, and access to water (seas, rivers). 5. Power correlates because Timbuktu and Cairo were major cultural
hubs, as well.

Complicity: An International Journal of Complexity and Education Volume 15 (2018), Number 1・pp. 5-18 
Figure 2: Excerpts from Example Lesson Plans. Students are invited to make observations about plants in the school grounds (a), and to explore their data as a network (b), ultimately to investigate relationships in an ecosystem. In this high school history lesson (c), students map global trade networks and learn about the effect of resource location on connections, and connections on power. The full plans can be located via the NiCE website ("Networks in Classroom Education (NiCE) Teacher Workshop," 2017).

\section{Outcomes: Findings and End Products}

The workshop was a vibrant, highly creative experience, which spurred lots of discussions about the utility of the lens of network thinking, both in lessons and in lesson/curriculum planning. In all, we received 13 exceptionally innovative resources for the teaching community. They comprise 10 lesson plans and 3 projects on network science in education (a professional development module, a plan to map an effective calculus revision guide, and a plan for a Social Network Analysis to improve management and organization). The resources are summarized in Table 2 and are all available online ("Networks in Classroom Education (NiCE) Teacher Workshop," 2017). Each utilizes network thinking in a way specific to the lesson, either by studying connections/relationships, explicitly considering a network, using a network concept, or employing a network tool as in the education projects.

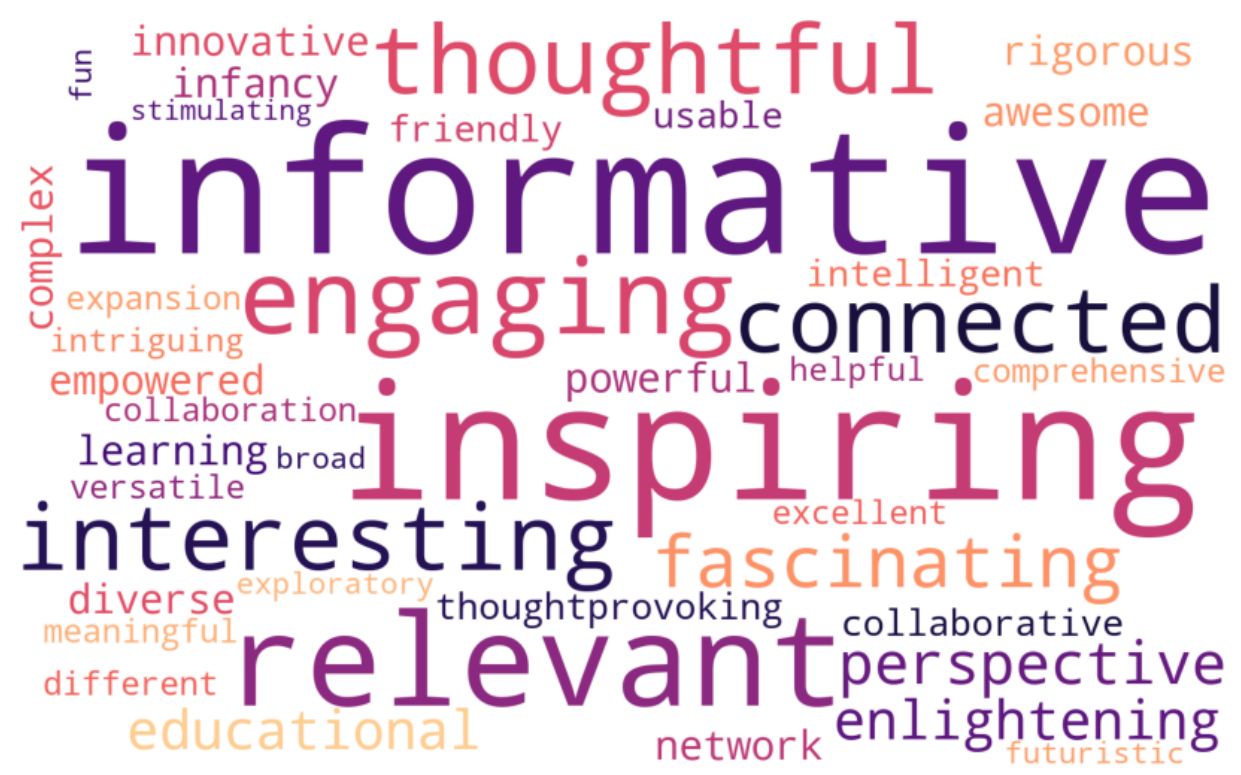

Figure 3: Wordcloud of Participants' Description of Their Overall Experience Size of the descriptors varies by frequency of mention.

Complicity: An International Journal of Complexity and Education

Volume 15 (2018), Number $1 \bullet p p .5$ - 18 
Table 2. Network Science in Education Resources Developed by Teachers

\begin{tabular}{|c|c|c|}
\hline \multicolumn{2}{|r|}{ Lesson plans } & \multirow{2}{*}{$\begin{array}{l}\text { Level } \\
\text { Middle }\end{array}$} \\
\hline Three skeleton key & $\begin{array}{l}\text { Reading and comprehension, considering the spread of } \\
\text { plague on a network in the Middle Ages. }\end{array}$ & \\
\hline $\begin{array}{l}\text { Depletion of fish in } \\
\text { oceans }\end{array}$ & $\begin{array}{l}\text { Comprehensive lesson drawing links between various } \\
\text { reading materials and acknowledging the interconnectedness } \\
\text { of factors harming the ocean ecosystems. }\end{array}$ & Middle \\
\hline $\begin{array}{l}\text { Balance networks in } \\
\text { music ensembles }\end{array}$ & $\begin{array}{l}\text { Identifying balance networks in a string orchestra, and how } \\
\text { alterations to the network change resultant sound. }\end{array}$ & High \\
\hline $\begin{array}{l}\text { Network science in } \\
\text { relationship } \\
\text { development }\end{array}$ & $\begin{array}{l}\text { Understanding and developing personal relationships and } \\
\text { strong communities through the lens of network science. }\end{array}$ & Elementary \\
\hline $\begin{array}{l}\text { Interdependent } \\
\text { relationships in an } \\
\text { ecosystem }\end{array}$ & $\begin{array}{l}\text { Exploring the connected factors at play in the growth and } \\
\text { survival of plants in the school grounds. }\end{array}$ & $\begin{array}{l}\text { Elementary } \\
\text { \& Middle }\end{array}$ \\
\hline Nanotechnology & $\begin{array}{l}\text { Use connections between words to clarify concepts and } \\
\text { meanings in a text, and then connections between claims and } \\
\text { reasoning to develop an argument. }\end{array}$ & Middle \\
\hline $\begin{array}{l}\text { The power of literate } \\
\text { people }\end{array}$ & $\begin{array}{l}\text { Exploring connections between reading, behavior, and } \\
\text { literacy. }\end{array}$ & Elementary \\
\hline $\begin{array}{l}\text { Applying network } \\
\text { science to resource } \\
\text { management }\end{array}$ & $\begin{array}{l}\text { Map the structure of resource reliance on common materials } \\
\text { and the relation to waste. }\end{array}$ & High \\
\hline Shark network & Consequences of the portrayal of sharks in the media. & Middle \\
\hline $\begin{array}{l}\text { Networks in world } \\
\text { history }\end{array}$ & $\begin{array}{l}\text { Examining trade networks, and the effect of globalization of } \\
\text { such networks with the Columbian Exchange. }\end{array}$ & High \\
\hline \multicolumn{2}{|r|}{ Projects on network science and education } & \\
\hline $\begin{array}{l}\text { Networking in a } \\
\text { calculus environment }\end{array}$ & $\begin{array}{l}\text { Analyze topics of questions in past } \mathrm{AP} \text { calculus exams to } \\
\text { design effective revision strategies. }\end{array}$ & High \\
\hline $\begin{array}{l}\text { Social network within } \\
\text { the school }\end{array}$ & $\begin{array}{l}\text { Map communication networks between staff, to improve } \\
\text { organization and management. }\end{array}$ & Teacher \\
\hline $\begin{array}{l}\text { Networking } \\
\text { interdisciplinary grade } \\
\text { level standards }\end{array}$ & $\begin{array}{l}\text { Professional development module. Generate network maps of } \\
\text { standards to identify opportunities for interdisciplinary } \\
\text { lessons and curriculum development. }\end{array}$ & Teacher \\
\hline
\end{tabular}

Please note that titles, brief summaries, and target level are provided. Lesson plans and projects can all be found on the NiCE website ("Networks in Classroom Education (NiCE) Teacher Workshop," 2017).

Complicity: An International Journal of Complexity and Education Volume 15 (2018), Number 1・pp. 5-18 
EMMA K. TOWLSON ET AL.
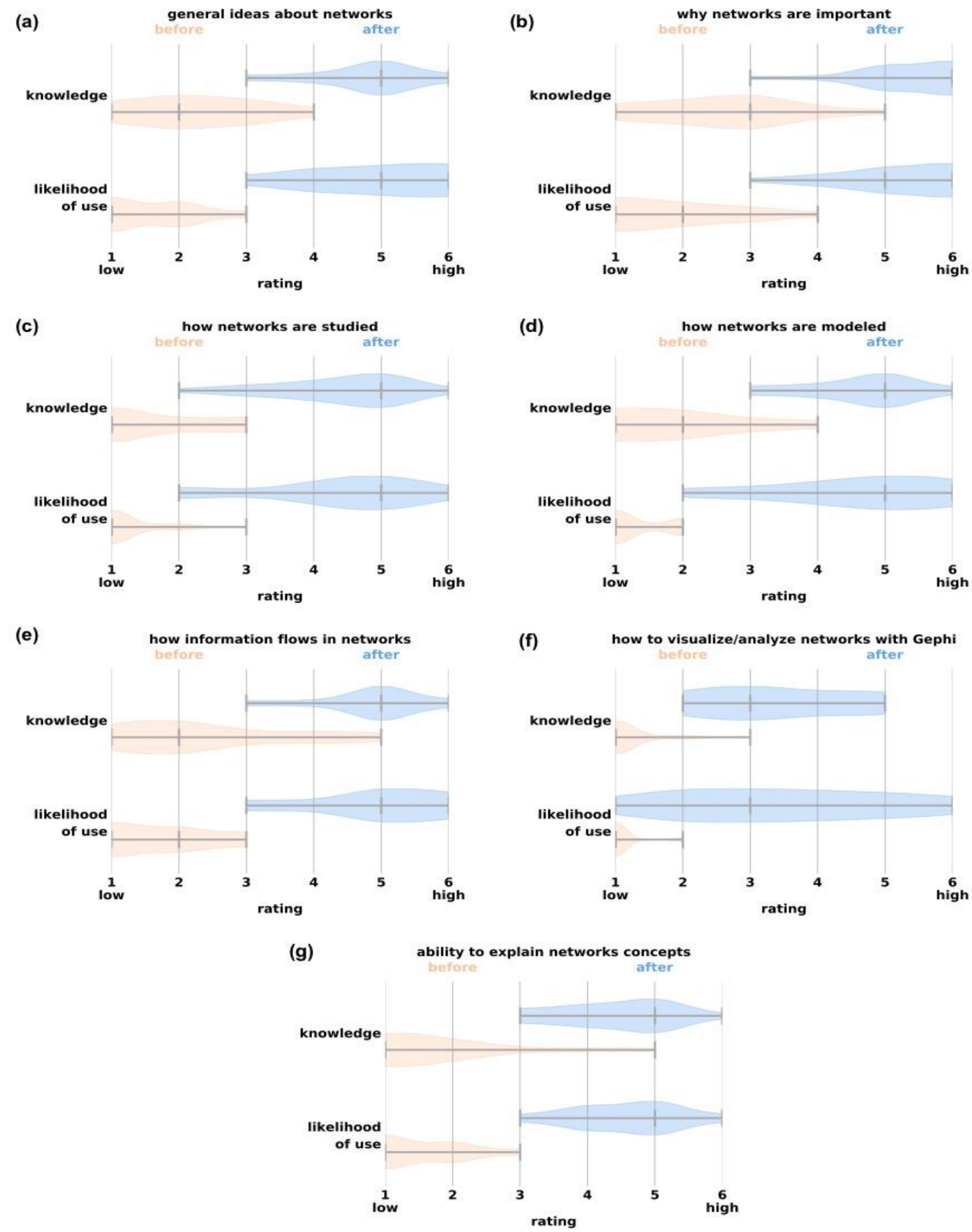

Figure 4. Violin Plots Illustrating Participants' Knowledge and Likelihood of Use of Networks, Before and After the Workshop. Ratings are illustrated on the x-axis, and the probability density

Complicity: An International Journal of Complexity and Education Volume 15 (2018), Number 1・pp. 5-18 
on the y-axis (qualitatively, this corresponds to the number of participants who gave a specific rating).

For example, one lesson aimed at elementary to middle school students explores the factors underpinning the survival of an ecosystem, using network science to explore the relationships between the data (see Figure $2(a-b)$ ). Students are invited to examine plants in the school grounds and note their properties, such as color, location, and scent. They are challenged to identify cause and effect, and in doing so, earn an integrative understanding of the local ecosystem. Another lesson, designed for high school history students, considers the globalization of trade networks (see Figure 2 (c)) ("Outline world map images," n.d.). By mapping these networks and considering areas of high traffic (ports and popular trading routes), one can elucidate the important connections and valuable resources. And indeed, how and why these connections formed, and their relationship with global political power.

At the end of the workshop survey the teachers were asked to describe their experience using only three words. The results are shown in Figure 3, with font sized by number of mentions. For reference, "informative" was put forward six times, and "stimulating" one time. Variations of the same concept (e.g. "educational" and "educationally") are aggregated into one representative word. Responses were overwhelmingly positive, providing a picture of a motivating and creative learning experience: the most commonly put forward words include "informative", "inspiring", "relevant", "thoughtful", "connected", and "interesting". Participants were further queried on a number of network science related points, such as "the importance of networks" (see Figure 4). Using a scale of 1-6, with 1 the lowest and 6 the highest, they were asked to rate (i) their knowledge of each point before the workshop; (ii) their knowledge of each point after the workshop; (iii) their likelihood to use each point in the classroom before the workshop; and (iv) their likelihood to use each point in the classroom after the workshop. In all cases, comparing before to after the workshop, there is a large increase in the ratings of both their understanding and their likelihood to make use of the network concept. This demonstrates the teachers' own perceptions of their new understanding of these network science concepts, and the success in motivating the teachers to use these concepts in their own classrooms. Of course it must be noted that these measures are highly subjective; perceived understanding is not necessarily true understanding, and personal decisions on how to report vary. Further, before the workshop almost all of the teachers had had very little exposure to network science concepts, and so are almost certain to report low ratings for "before" the workshop, especially for likelihood of use. The "before" ratings therefore serve as a baseline, a difference from which indicates a perceived increase in knowledge and likelihood to use. Nevertheless, we can conclude that the teachers enjoyed a positive and intense learning experience, and returned to their schools highly motivated to put some of their new knowledge into practice.

\section{Discussion and Outlook}

Successful integration of network science and network-thinking with high school education necessarily relies on educators. There is currently a lack of material to use in lesson design,

Complicity: An International Journal of Complexity and Education

Volume 15 (2018), Number $1 \bullet p p .5$ - 18 
presenting a need and an opportunity. The best resources, including lesson plans, will be developed via collaborative efforts between teachers and network scientists, thus bringing together the experience, knowledge, skillsets, and ways of thinking of both types of experts. To make it worthwhile for teachers to invest in such efforts on top of their existing demands, the payoff to them of applying network science concepts in their work must be made explicit. Lesson content can be created that cuts across concepts and curricular subjects and satisfies the governmental standards. This facilitates collaboration with other teachers and departments, increases creativity, and eases workload. Further, network science can be a valuable tool in understanding and effectively implementing these standards (in particular, the interconnected criteria in the NGSS).

Our workshop demonstrated a proof-of-principle, clearly eliciting great enthusiasm for network-thinking from the participating teachers. Moreover, it led to the design of several creative and potentially extremely useful module and lesson plans. In future efforts, such plans could be adapted to cater to any grade level. Finally, most participants articulated an intention to take what they had learned back to their home institutions. Whilst we have exposed the need, enthusiasm, and motivation to develop network science related educational resources, more details remain to be understood. We do not yet have a reliable quantitative measure to assess the extent of the teachers' new knowledge and understanding, and the strengths and weaknesses of the actual implementations of the developed lesson plans should be explored in further efforts. A longer-term study would be interesting to interrogate the benefits to teachers in using network science approaches to meet official standards and connect modules and subjects.

We will expand on this foundation and initial cohort and continue to pursue our aim to inspire and empower teachers to take ownership of the network lens for their classrooms. Explicit next steps include gaining support to conduct more of these kinds of workshops with specific audiences, such as underserved immigrant and underrepresented populations, and provide increased opportunity to develop and validate a broad set of resources, tools, lesson and unit plans, and to grow the community of practice in network science teaching and learning. As datadriven sciences burgeon throughout the range of disciplines, the need for complementary techniques and resources will become increasingly urgent to adequately prepare the next generation of teachers and learners.

\section{Acknowledgements}

We gratefully acknowledge conference support from the US Army Research Office: “Network Science and Education", and from the West Point Network Science Center. We thank all of the teachers who came to West Point to participate in this workshop and shared their passion, experience, and efforts to produce the resources we present here.

\section{References}

Barabási, A. L. (2016). Network Science. Cambridge University Press.

Bassett, D. S., \& Mattar, M. G. (2017). A Network Neuroscience of Human Learning: Potential to Inform Quantitative Theories of Brain and Behavior. Trends in Cognitive Sciences.

Complicity: An International Journal of Complexity and Education

Volume 15 (2018), Number 1・pp. 5-18 
https:/ / doi.org/10.1016/j.tics.2017.01.010

Cramer, C., Gera, R., Labriole, M., Sayama, H., Sheetz, L., Towlson, E., \& Uzzo, S. (2018). Cultivating Tipping Points: Network Science in Teaching. In CompleNet 2018: Complex Networks IX (pp. 175-183).

Cramer, C., Porter, M. A., Sayama, H., Sheetz, L., \& Uzzo, S. (n.d.). Network Literacy: Essential Concepts and Core Ideas. NetSciEd. Retrieved from https://sites.google.com/a/binghamton.edu/netscied/teaching-learning/networkconcepts

Cramer, C., Sheetz, L., Sayama, H., Trunfio, P., Stanley, H. E., \& Uzzo, S. (2015). NetSci High: Bringing Network Science Research to High Schools. Complex Networks VI Proceedings of the 6th Workshop on Complex Networks CompleNet 2015. https://doi.org/http://dx.doi.org/10.1007/978-3-319-16112-9_21

Harrington, H. A., Beguerisse-Díaz, M., Rombach, M. P., Keating, L. M., \& Porter, M. A. (2013). Commentary: Teach network science to teenagers. Network Science, 1(2), 226-247. https:// doi.org/10.1017/nws.2013.11

Networks in Classroom Education (NiCE) Teacher Workshop. (2017). Retrieved from https:// sites.google.com/a/binghamton.edu/nice-teacher-workshop/home

Next Generation Science Standards (NGSS). (n.d.).

Outline world map images. (n.d.). Retrieved from www.outline-world-map.com\%0D

Sayama, H., Cramer, C., Porter, M. A., Sheetz, L., \& Uzzo, S. (2016). What are essential concepts about networks? Journal of Complex Networks, 4(3), 457-474. https://doi.org/10.1093/comnet/cnv028

Sayama, H., Cramer, C., Sheetz, L., \& Uzzo, S. (2017). NetSciEd: Network Science and Education for the Interconnected World. Complicity: An International Journal of Complexity and Education, 14(2), 104115.

Sheetz, L., Dunham, V., \& Cooper, J. (2015). Professional development for network science as a multi-disciplinary curriculum tool. In ISEC 2015 - 5th IEEE Integrated STEM Education Conference (pp. 178-182). https:/ / doi.org/10.1109/ISECon.2015.7119919

\section{About the Authors}

Emma K. Towlson is an Associate Research Scientist at the Center for Complex Network Research (CCNR), Northeastern University. Her research interests lie in network neuroscience, an emergent discipline at the intersection of network science and neuroscience. She instructs a graduate level course in network science, which she has tailored to suit students of differing and diverse skillsets and levels of exposure to scientific approaches. Correspondence: ektowlson@gmail.com

Lori Sheetz is the Director of the STEM Outreach Initiatives at the United States Military Academy and a collaborator with the Network Science Center at West Point. Her expertise and interests include STEM education, outreach, and research with a special interest in bringing the study of networks and network science to K-16 students.

Complicity: An International Journal of Complexity and Education

Volume 15 (2018), Number $1 \bullet p p .5$ - 18 
Ralucca Gera is the Associate Provost for Graduate Education, and Professor of Mathematics at the Naval Postgraduate School. Ralucca is also a researcher in the Center for Cyber Warfare at the Naval Postgraduate School, as well as an associate researcher in the Network Science Center at United States Military Academy. Her research interests are in graph theory and network science, with applications to the study of the Internet, Cyber networks and Natural Language Processing, sponsored by DoD organizations.

Jonathan W. Roginski has served over twenty two years in the United States Army, with the past twelve years learning and applying analytical decision support techniques to complex problems that support timely solutions to Department of Defense problems.

Catherine B. Cramer has spent over twenty years engaged in public science education and identifying, creating, sustaining and growing productive and innovative collaborations and partnerships among research, industry and academia, with a particular focus on developing tools for the teaching and learning of complex network and data science.

Stephen Uzzo is a Chief Scientist at the New York Hall of Science. His expertise and interests include research and development of public programs and experiences on complexity science, network models for learning, collaboration in free choice learning environments, and the teaching and learning of data driven science.

Hiroki Sayama is a Professor in the Department of Systems Science and Industrial Engineering, and the Director of the Center for Collective Dynamics of Complex Systems (CoCo), at Binghamton University, State University of New York. His expertise and interests include complex dynamical networks, human and social dynamics, collective behaviors, artificial life/chemistry, interactive systems, and complex systems education, among others.

Complicity: An International Journal of Complexity and Education

Volume 15 (2018), Number 1・pp. 5-18 